\title{
Procedimentos de segurança para o manuseio correto e consciente de lâmpadas de vapor
}

\author{
Safety procedures for the correct and conscious handling of pressure steam lamps
}

\author{
Raphael Alves dos Santos ${ }^{\dagger *}$, Luis Fernando Raposo Arvellos ${ }^{\dagger}$, Alex Franco Ferreira ${ }^{\dagger}$, José Thomaz de \\ Carvalho $^{\dagger}$
}

Como citar esse artigo. dos Santos RA; Arvellos LFR; Ferrerira, AF; de Carvalho JT. Procedimentos de segurança para o manuseio correto e consciente de lâmpadas de vapor. Revista Teccen. 2017 Jul/Dez.; 10 (1): 03-12.

\section{Resumo}

Com a regulamentação da Lei de Eficiência Energética, que induziu ao banimento gradativo das lâmpadas incandescentes e a substituição pelas lâmpadas fluorescentes, as quais são mais eficientes do ponto de vista energético, a quantidade de lâmpadas fluorescentes geradas devido à essa substituição das incandescentes por fluorescentes aumentou a quantidade deste tipo de lâmpadas. Além disso, devido também a substituição das fluorescentes por LED, que são ainda mais eficientes, tornou-se o manuseio para substituição e descarte ainda maior. Além das fluorescentes, outros modelos de lâmpadas de vapor tubulares e ovóides são utilizadas em áreas de iluminação pública. O mercúrio é um componente essencial para o funcionamento das lâmpadas fluorescentes e lâmpadas de vapor de mercúrio, e está relacionado à longa vida útil e à eficiência energética. Porém, é um elemento de alto efeito tóxico e cumulativo. O vidro é outro componente utilizado nestas lâmpadas e oferece riscos de acidente durante seu manuseio para instalação, retirada, armazenamento e descarte. Torna-se necessário realizar uma análise dos riscos oferecidos pelo manuseio incorreto, tanto ao meio ambiente quanto à saúde física dos profissionais da área, focando nos procedimentos de segurança para o manuseio correto e consciente de lâmpadas de vapor. Este trabalho traz informações necessárias para o entendimento dos riscos oferecidos e das medidas de segurança que devem ser adotadas para os profissionais da área de eletricidade e manutenção que mantém contato diretamente ou indiretamente com lâmpadas de vapor. O presente artigo apresenta um estudo com base em consultas e registros fotográficos de campo sobre o atual cenário da forma incorreta de manuseio e descarte praticada pela sociedade. Tem por objetivo destacar a importância conscientização dos riscos existentes, para aplicação das medidas de segurança que serve de referência para aplicação em empresas e residências. Considera-se que a visão geral proporcionada por este trabalho permitirá razoável posicionamento do leitor quanto às ações de operacionalização na segurança no manuseio correto lâmpadas de vapor para melhoria das atuais formas de manuseio e descarte para um processo de trabalho mais seguro.

Palavras-Chave: Lâmpadas de vapor; Manuseio correto; Segurança. Fonte: (SILVA, 2013).

\begin{abstract}
With the regulation of the Energy Efficiency Law, which led to the gradual banning of incandescent bulbs and replacement by fluorescent lamps, which are more energy efficient, the amount of fluorescent bulbs generated due to this replacement of incandescent fluorescents increased The quantity of this type of lamps. In addition, due also to the replacement of fluorescents by LED, which are even more efficient, has become the handling for further replacement and disposal. In addition to fluorescents, other models of tubular and ovoid vapor lamps are used in public lighting areas. Mercury is an essential component for the operation of fluorescent lamps and mercury vapor lamps, and is related to long life and energy efficiency. However, it is an element of high toxic and cumulative effect. Glass is another component used in these lamps and offers a risk of accident during its handling for installation, withdrawal, storage and disposal. It is necessary to carry out an analysis of the risks offered by the incorrect handling, both to the environment and the physical health of the professionals of the area, focusing on safety procedures for the correct and conscious handling of steam lamps. This work brings information necessary to understand the risks offered and the safety measures that must be adopted for professionals in the area of electricity and maintenance who maintains contact with steam or vapor lamps directly. The present article presents a study based on consultations and photographic field records about the current scenario of the incorrect handling and disposal practices practiced by society. It aims to highlight the importance of awareness of the existing risks, to apply the security measures that serve as reference for application in companies and residences. It is considered that the overview provided by this work will allow reasonable positioning of the reader regarding the actions of operationalization in the safety in handling correct vapor lamps for improvement of the current forms of handling and disposal for a safer working process.

Keywords: Steam lamps; Correct handling; Safety.
\end{abstract}




\section{Introdução}

As questões de segurança do trabalho há tempos são discutidas devido à necessidade de se tomar medidas segurança para proteção dos trabalhadores. A concientização das medidas de segurança, normas regulamentadores e procedimentos de trabalho por parte das empresas e da população é considerada fundamental para que se alcance uma qualidade de vida no trabalho, diminuindo os danos causados pelo manuseio irresponsável e pelo armazenamento inadequado das lâmpadas de vapor.

Medidas podem ser tomadas pela sociedade e pelas empresas para que sejam responsáveis. Entre elas está a conscientização dos riscos e o uso de equipamentos de proteção coletiva - EPC e equipamentos de proteção individual - EPI.

Devido a competitividade global das empresas ocorre a inovação tecnológica em um espaço mais curto de tempo. Nos últimos anos, um novo modelo lâmpadas foi introduzido no mercado e sua comercialização está crescendo no mundo. $\mathrm{O}$ LED (Diodo Emissor de Luz) vem sendo utilizado nas lâmpadas com o objetivo de ser uma luminária alternativa as lâmpadas convencionais em busca da redução do consumo e conseqüentemente dos custos de energia elétrica. É a partir desse quadro que surge um aumento um aumento exponencial do problema de manuseio para substituição e descarte de lâmpadas de vapor.

A gestão de lâmpadas de vapor, manuseio para transporte, sua instalação e retirada para substituição, armazenamento e descarte, ou seja, da fabricação até a disposição final, têm sido um constante desafio colocado aos profissionais da área. A preocupação com a questão ambiental também torna o gerenciamento de resíduos de lâmpadas um processo de extrema importância na preservação da qualidade da saúde e do meio ambiente.

Assim, torna-se relevante avaliar de que maneira as empresas e a população geral podem contribuir para combater o problema do manuseio correto e consciente destas lâmpadas através de procedimentos de segurança adequados, questionamentos que orientam este estudo.

Além de evidenciar as possibilidades de contribuição das empresas e da sociedade nesse contexto, este estudo torna-se relevante ao discutir a gestão deste resíduo, temas ainda incipientes no âmbito acadêmico, contribuindo para o desenvolvimento de estudos futuros.

Visto a importância de um estudo sobre a disposição correta de lâmpadas vapor, após flagrar em alguns locais o manuseio, a disposição e armazenamento totalmente incorreto de lâmpadas e a falta de comprometimento da sociedade sobre a elaboração de um sistema de gestão para manuseio devido, surgiu-se a motivação para atuar nessa problemática de forma a ajudar a propagar a importância da conscientização dos riscos existentes. A iniciativa de elaborar este trabalho surgiu do interesse de analisar detalhadamente, não só o transporte para instalação desse tipo de material, mas também a forma em que este deve ser armazenado, transportado e como ocorre a reciclagem deste produto, buscando elucidar essas informações obtidas através deste estudo para elaboração de uma cartilha e um manual de conscientização para facilitar o entendimento das pessoas sobre a importância dos procedimentos de segurança corretos.

Assim, o presente trabalho tem como objetivo geral apresentar um estudo sobre a forma em que são manuseadas e descartadas as lâmpadas de vapor em empresas e em residências, para análise dos riscos ambientais e à saúde e assim verificar a forma do manuseio e descarte corretos. Considerando-se que deve haver um procedimento a seguir para evitar este risco, o trabalho de conscientização da população é uma alternativa para evitar acidentes em todos os processos que envolvem o manuseio destas lâmpadas.

\section{Lâmpadas de vapor}

Segundo Ferreira (2010), os tipos de lâmpadas podem ser classificados em: lâmpadas incandescentes, lâmpadas halógenas, lâmpadas fluorescentes, lâmpadas de descargas, lâmpadas LED e lâmpadas de fibra óptica. A seguir são apresentados os conceitos básicos das lâmpadas pertinentes, relevantes para o estudo desenvolvido.

As lâmpadas fluorescentes funcionam a base de gases, trifósforos (combinação de fósforos e terras raras) para possibilitar alta eficiência, boa aparência e baixo consumo. Reatores são necessários. Para classificação desta lâmpada existem quatro grupos: Tubulares, eletrônicas (reatores integrados), circulares e compactas. Segundo Ferreira (2010), a eficiência nesse tipo de lâmpada é alta, apresenta vida útil de 7.500 a 10.000 horas. Esse tipo de lâmpada é preferencialmente de uso residencial e comercial.

As lâmpadas de descarga funcionam através de uma descarga (alta pressão) elétrica entre os eletrodos, leva os componentes internos (gases sódio, xenon, mercúrio) do tubo de descarga a produzirem luz, levam reatores e ignitores em sua composição.

Para classificação desta lâmpada existem: Multivapores metálicos, Vapor de sódio, Vapor de sódio branca, Vapor de Mercúrio e Mistas.

A Figura 1.1 mostra exemplos de lâmpadas fluorescentes e lâmpadas de descarga. 


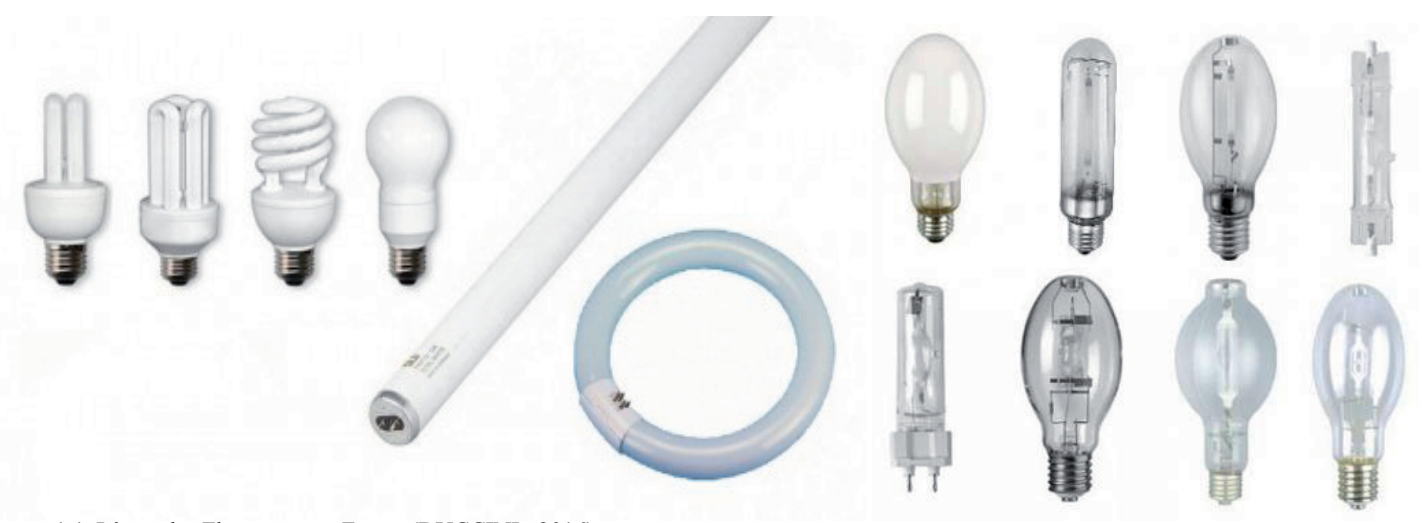

Figura 1.1. Lâmpadas Fluorescentes Fonte: (DUCCINI, 2016).

A regulamentação da Lei de Eficiência Energética, através da Portaria Interministerial $\mathrm{n}^{\circ}$ 1.007 , induziu ao banimento gradativo das lâmpadas incandescentes e a substituição pelas lâmpadas fluorescentes, as quais são mais eficientes do ponto de vista energético. A quantidade de LFs geradas devido à essa substituição das incandescentes por fluorescentes aumentou a quantidade deste tipo de lâmpada. Além disso, devido também a substituição das fluorescentes por LED, que são ainda mais eficientes, tornou-se o manuseio para descarte ainda maior.

Porém, do ponto vista ambiental, há um diferencial entre as lâmpadas incandescentes e fluorescentes, refere-se ao teor de mercúrio, existente somente nas fluorescentes.

Logo, torna-se necessário procedimentos de segurança adequados para o manuseio e também um sistema de logística reversa e de reciclagem deste material, bem como uma política de conscientização da população e das empresas quanto aos riscos gerados pela exposição ao mercúrio e vidro contidos nas lâmpadas, sejam elas resíduos residenciais ou industriais.

\section{Segundo Silva (2013):}

"Uma lâmpada fluorescente tubular é composta, basicamente, por um tubo de vidro recoberto internamente por pós de fósforo. Nas duas extremidades da lâmpada, são instalados eletrodos, construídos em tungstênio ou aço inoxidável, como mostra a Figura 1.2, ilustrando o lado de uma da lâmpada. Finalmente, no interior do tubo, que se encontra em vácuo parcial $(0,003 \mathrm{~atm})$, encontra-se uma mistura gasosa constituída por um gás inerte (tal como argônio, neônio, criptônio e/ou xenônio), e vapor de mercúrio."

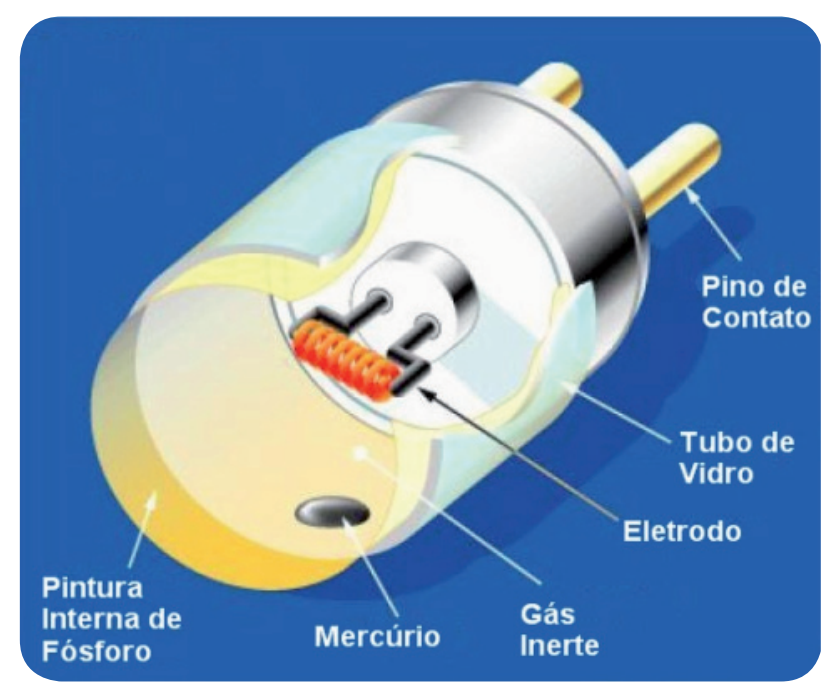

Figura 1.2. Perfil de uma lâmpada fluorescente. Fonte: (SILVA, 2013).

\section{Riscos à saúde e meio ambiente}

Segundo Lima, Colon \& Souza (2009):

\footnotetext{
"No estudo que trata das alterações auditivas em trabalhadores expostos ao mercúrio, foi verificado que dentre os metais pesados, o uso do mercúrio nos ambientes de trabalho traz uma preocupação em relação à saúde do trabalhador. O autor declarou que a concentração de mercúrio no ar alterase de acordo com a temperatura, sendo que a evaporação é maior quanto mais elevada for esta última, e por ser um líquido extremamente volátil, a absorção do vapor de mercúrio se dá principalmente pela via inalatória, sendo o cérebro e o rim os locais de maior deposição. Lima, Colon \& Souza (2009) também citaram que pode ser absorvido através da pele íntegra (sendo o único metal absorvido na forma metálica), em função de uma série de características físico-químicas peculiares, principalmente em relação à volatilidade mesmo a baixas temperaturas. De acordo com Lima, Colon \& Souza (2009), para verificar a exposição excessiva ao metal em sua forma metálica deve-se analisar de forma biológica a dosagem do mercúrio na urina. As alterações que ocorrem no corpo humano pela intoxicação do mercúrio metálico, também denominada hidrargirismo,
} 
são decorrentes de lesões que podem acometer o sistema nervoso central, fígado, medula óssea, vias aéreas superiores, pulmão, gengiva, pele, parede intestinal, glândulas salivares, coração, músculos, placenta e rim. A manifestação pode se dar de forma aguda ou crônica, após exposição intensa ou prolongada. $\mathrm{O}$ autor conclui em seu estudo que o mercúrio pode agredir tanto o sistema auditivo periférico ou central."

No estudo realizado por Silva (2013), também foi informado que o mercúrio é o mais volátil de todos os metais, e na forma de vapor é altamente tóxico, sendo necessário ventilação forçada e ambientes fechados se o mercúrio for usado.

Em uma entrevista realizada por Carneiro (2010), verificou-se que:

"Ao perguntar ao proprietário de uma empresa de reciclagem
sobre como define a gestão ambiental, tanto pública,
quanto privada, no processo de reciclagem de lâmpadas, o
proprietário assinalou que: "Não existe hoje, tirando um ou
outro município, leis e procedimentos que regulamentem
a destinação de lâmpadas no país. Hoje a destinação é
feita de uma consciência da empresa. Então a maior parte
dos meus clientes são empresas que tem ISO 14.000 "."

Cuidados devem ser tomados na reciclagem do vidro proveniente desse resíduo, uma vez que ele também apresenta mercúrio, o qual é extraído a temperaturas altas desse material. Também a utilização desse vidro para outros fins quaisquer, como armazenamento de bebidas ou confecção por crianças e adolescentes do conhecido cerol utilizado em linhas de pipas, apresenta um potencial risco.

Júnior e Widmoller (2008) afirmam que:

"É de suma importância que a reciclagem esteja amparada por recursos tecnológicos que permitam a recuperação eficaz desses constituintes, em especial o mercúrio, uma vez que esse metal, apesar de essencial para o funcionamento das lâmpadas fluorescentes, é altamente tóxico. O IBAMA é o órgão do Ministério do Meio Ambiente responsável por fiscalizar e executar a política ambiental. Dentre seus objetivos pode-se destacar o de "promover a adoção de medidas de controle de produção, utilização, comercialização, movimentação e destinação de substâncias químicas e resíduos potencialmente perigosos"."

Bastos (2011) citou Zahir (2005), que disse que: rapidamente absorvido através de vias respiratórias (cerca de $80 \%$ ), mas pouco por vias gastrointestinais (aproximadamente $0,01 \%$ ) e apenas de forma muito limitada através da pele. Formas orgânicas de mercúrio são, no entanto, facilmente absorvidas por inalação e do por vias gastrointestinais, onde aproximadamente $95 \%$ do metilmercúrio ( $\mathrm{MeHg}$ ) presentes em farinha de peixe pode ser absorvido.

Em seu estudo Bastos (2011) mostrou que:

\begin{abstract}
"No Brasil, as lâmpadas que contêm mercúrio, após o uso, são classificadas como resíduos perigosos (Classe 1) pela Norma ABNT 10.004/04. Diante disto, merecem cuidados especiais quanto aos procedimentos de manuseio (retirada/coleta), acondicionamento, transporte, armazenagem e destinação final, em função das suas características peculiares e dos riscos que apresentam. Bastos (2011) finalizou mostrando em seu trabalho que a substituição de lâmpadas incandescentes por LFs gerou aumento de emissão de mercúrio, de distorções harmônicas e redução de fator de potência na rede." 3
\end{abstract}

\section{Medidas de Educação ambiental}

A Política Nacional de Resíduos Sólidos também cita a necessidade de elaborar programas e ações de educação ambiental que promovam a não geração, a redução, a reutilização e a reciclagem de resíduos sólidos.

Considerando-se o descarte médio de 200 milhões de lâmpadas em todo Brasil, ao multiplicarse essa grande quantidade pela pequena quantidade de mercúrio existente em casa lâmpada, conclui-se que este resíduo causa um grande dano ao meio ambiente.

Uma sugestão para a conscientização deste problema seria a promoção de cursos de educação ambiental abordando especificamente sobre lâmpadas fluorescentes, em feira, campanhas, cursos etc.

O descarte de lâmpadas que contém mercúrio tem aumentado e isto requer portanto, uma atenção especial, para evitar que o mercúrio contamine o ar, solo e água.

\section{Medidas de segurança para manuseio e armazenamento}

Para o manuseio e armazenamento de lâmpadas, Silva (2013) afirma o seguinte

\footnotetext{
"O manuseio incorreto de lâmpadas que contém mercúrio e a exposição a este elemento tóxico é grave. Torna-se necessário uma conscientização ambiental da população, referente aos danos deste resíduo ao meio ambiente e principalmente dentro de suas residências e seus locais de trabalho. Para acondicionamento correto de lâmpadas contendo mercúrio deve-se seguir alguns procedimentos, como: - Não quebrar as lâmpadas. No caso de lâmpadas quebradas acidentalmente durante o manuseio deve-se realizar a assepsia
} 
(evitar ou remover a contaminação) do local e armazená-las em caixas especificas, fechadas e revestidas internamente com sacoplástico para evitar sua contaminação, comaidentificação de Lâmpadas de mercúrio quebradas - Produto tóxico. -Estocarseparadamenteaslâmpadasquenãoestejamquebradas em uma caixa (preferencialmente sua embalagem original) - Colocar rótulos de identificação nas caixas - Enviar as lâmpadas para a descontaminação e reciclagem com as informações: nome do fornecedor, da transportadora e reciclador, número de lâmpadas e data do envio. Paraas lâmpadas queserãoacondicionadas inteiras recomenda que sejam embaladas individualmente, colocando-as preferencialmente em suas embalagens originais, mantendoas intactas e protegidas contra eventuais choques que possam provocar a sua ruptura, e armazená-las em local seco. Todo o mercúrio existente em uma lâmpada está contido e selado em seu interior. Na fase de manuseio, em particular, o pontofundamentalégarantiraintegridadedalâmpada,demodo que este mercúrio não migre para o ambiente. Trabalhadores sujeitos à contínua exposição, como os responsáveis pela substituição de lâmpadas queimadas, devem utilizar máscaras contra poeira, de modo a minimizar os riscos de exposição."

\section{Medidas de segurança para transporte de lâmpadas}

Para o transporte de lâmpadas, Silva (2013) afirma o seguinte

\begin{abstract}
"Para minimizar o risco de ruptura de lâmpadas durante o transporte, algumas empresas especializadas preferem realizar uma moagem simples das lâmpadas, no ponto de geração, de modo a transportar as lâmpadas moídas em recipientes lacrados inteiramente tapados de maneira a impedir a passagem de ar. A figura 1.3 a seguir ilustra um sistema Sistema Bulb Eater para moagem de lâmpadas no ponto de armazenamento do resíduo pelo gerador."
\end{abstract}

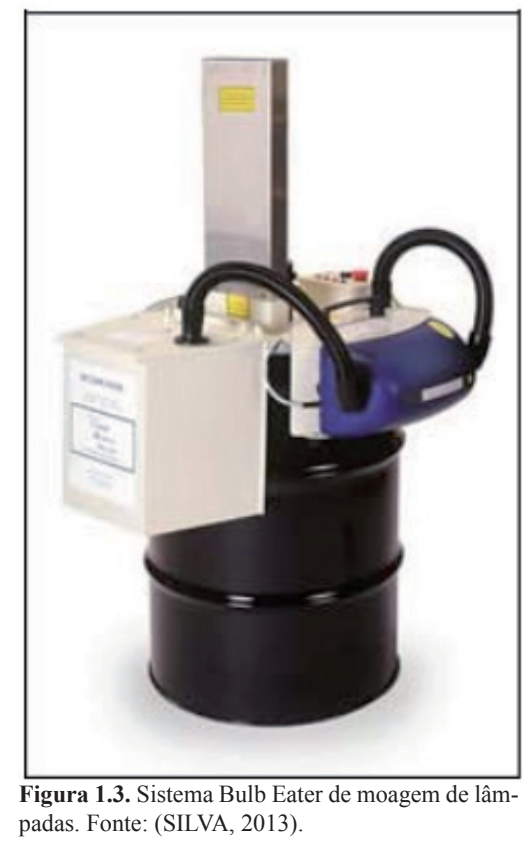

\section{Riscos associados a reutilização de componentes}

\begin{abstract}
Silva (2013) afirma o seguinte
"Usualmente, as partes de vidro e metais das lâmpadas fluorescentes são encaminhadas para reciclagem. Estes materiais, porém contém ainda certa quantidade de mercúrio, que chegam a $1,3 \mathrm{mg} / \mathrm{kg}$, no caso dos vidros, e $20 \mathrm{mg} / \mathrm{kg}$, no caso dos metais. Os processos de reciclagem de ambos os materiais podem envolver o aquecimento destes, levando a um risco potencial de emanações de mercúrio para o ambiente."
\end{abstract}

\section{Material a método}

Com o objetivo de verificar o procedimento adotado por algumas empresas referente a problemática do descarte correto de lâmpadas, foram realizadas pesquisas de campo em empresas, denominadas nestes trabalho como: empresa A e empresa B, cujas características do sistema de iluminação atual são em grande parte de lâmpadas fluorescentes tubulares.

Na empresa A, constituída de um prédio de 4 andares, foi constatado um grande número de lâmpadas fluorescentes tubulares armazenadas em alguns conjuntos, cada conjunto formado por diversas lâmpadas empilhadas, encostadas em paredes. O local do armazenamento trata-se de um subsolo, que serve de estacionamento, onde são estocados diversos tipos de equipamentos sem utilidade, as lâmpadas ficam expostas no prédio, algumas já foram danificadas e quebradas, poluindo o meio ambiente e oferecendo riscos de acidente e contaminação aos trabalhadores do local que utilizam o estacionamento.

A Figura 1.4 ilustra o armazenamento indevido no estacionamento da empresa A.

Em uma empresa de médio porte denominada empresa B, formada por um prédio onde estão localizadas a fábrica e o administrativo além de um galpão anexo que serve de oficina e estoque dos materiais fabricados, foi constatado um grande número de lâmpadas fluorescentes tubulares armazenadas em alguns conjuntos, cada conjunto formado por diversas lâmpadas, amarradas e expostas verticalmente apoiadas sobre a parede. O local do armazenamento trata-se de um galpão fechado, onde são armazenadas ferramentas de trabalho e diversos tipos de equipamentos sem utilidade, as lâmpadas não ficam expostas às intempéries, não foram verificadas lâmpadas danificadas e quebradas, porém o local oferece riscos de acidente e contaminação aos trabalhadores do local, além de obstruir a passagem para acesso aos materiais e ferramentas armazenadas.

A Figura 1.5 ilustra o armazenamento indevido no galpão de ferramentas e materiais da empresa B.

Além de armazenamento indevido em empresas, foi verificado e registrado também o tratamento indevido 


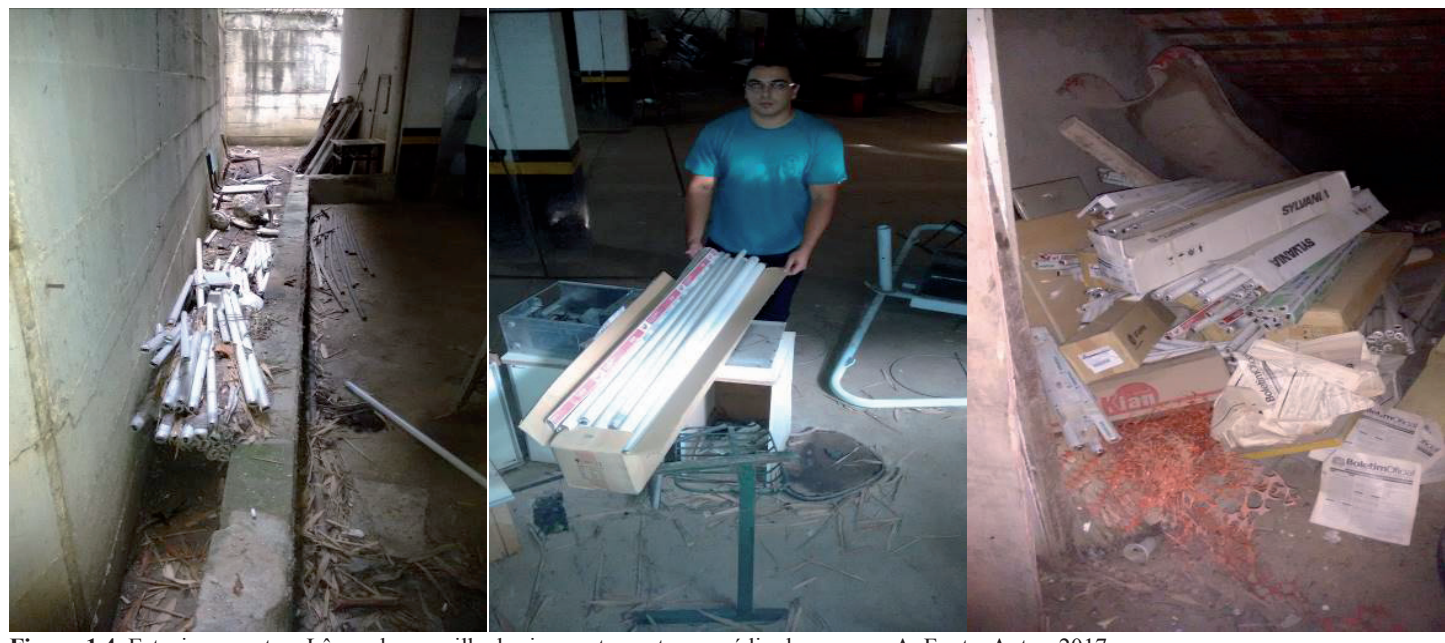

Figura 1.4. Estacionamento e Lâmpadas empilhadas incorretamente no prédio da empresa A. Fonte: Autor, 2017.

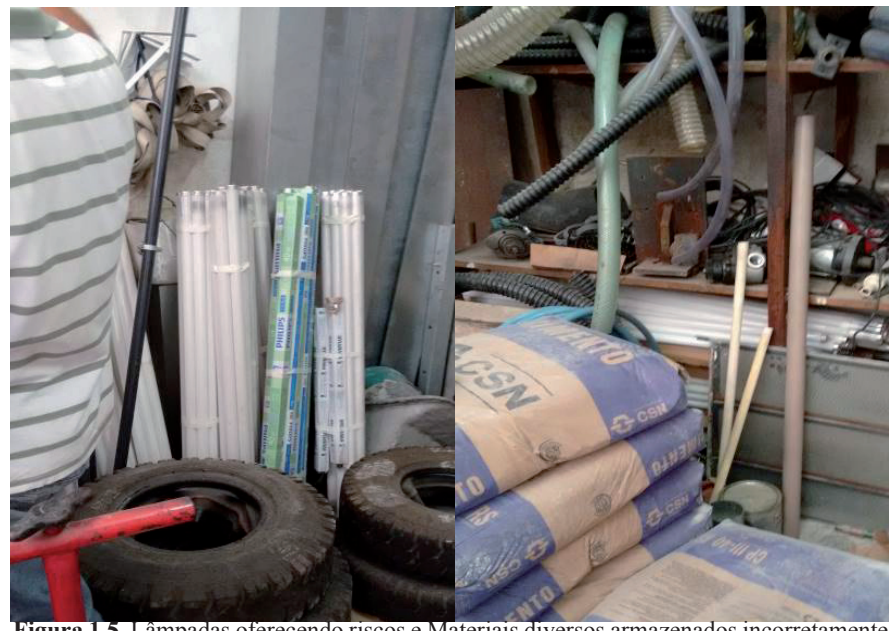

Figura 1.5. Lâmpadas oferecendo riscos e Materiais diversos armazenados incorretamente na empresa B. Fonte: Autor, 2017.

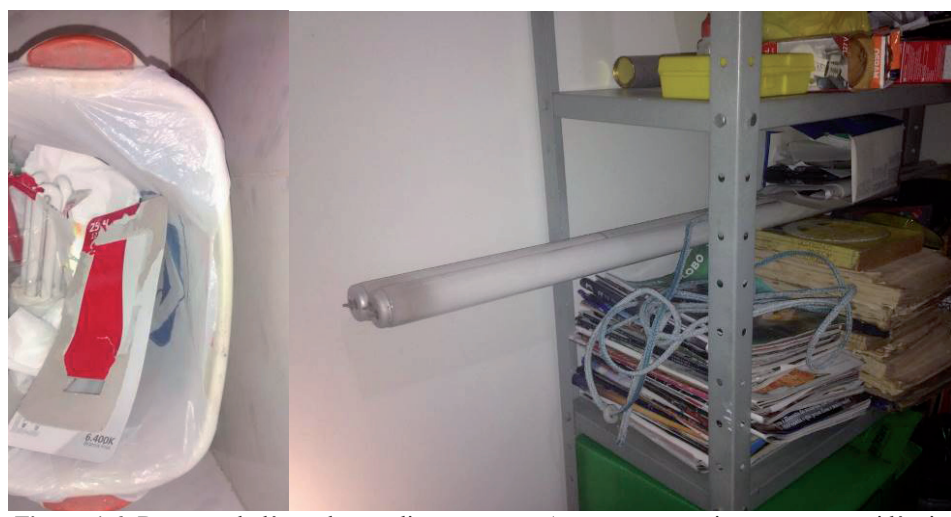

Figura 1.6. Descarte de lâmpadas em lixo comum e Armazenamento incorreto em residência Fonte: Autor, 2017.

de lâmpadas compactas em lixo comum residencial.

A Figura 1.6 ilustra o armazenamento e o descarte indevido de lâmpadas fluorescentes em unidades residenciais.

\section{Aplicação das medidas de segurança pós consumo de lâmpadas fluorescentes}

Neste capítulo, estão apresentados os trabalhos realizados para manuseio e armazenamento adequado 
de lâmpadas fluorescentes realizado na empresa A. Os materiais necessários para a realização dos trabalhos foram:

- Luva nitrílica de proteção;

- Óculos de proteção;

- Máscara de proteção PFF 1;

- Vestimenta de proteção;

- Container para armazenamento das lâmpadas (neste caso uma sucata de armário metálico, que estava inutilizado na empresa B);

- Tinta na cor laranja;

- Papelão;

- Fita plástica;

- Placa de sinalização com os dizeres "Resíduos perigosos";

- Placa de sinalização com a simbologia de identificação do resíduo e rótulo de risco para produtos tóxicos.

- Painel de segurança com a numeração para transportes de resíduos de LFs "60 2025";

- Ficha de informações necessárias sobre o resíduo, contendo informações como: Gerador do resíduo, quantidade de lâmpadas armazenadas, empresa responsável pela coleta e transporte do resíduo, data do transporte.

AABNT NBR 7500:2000 trata dos símbolos de risco e manuseio para o transporte e armazenamento de materiais. No anexo A desta NBR são apresentados os rótulos de risco de acordo com as classes, podendo ser: Classe 1 - Explosivos; Classe 2 - Gases; Classe 3 - Líquidos inflamáveis Classe 4 - Sólidos inflamáveis; substâncias sujeitas a combustão espontânea; substâncias que, em contato com a água, emitem gases inflamáveis; Classe 5 - Substâncias oxidantes e peróxidos orgânicos; Classe 6 - Substâncias tóxicas (venenosas) e substâncias infectantes; Classe 7 Materiais radioativos; Classe 8 - Corrosivos; Classe 9 - Substâncias perigosas diversas. Para resíduos de Lâmpadas fluorescentes a simbologia empregada é a mostrada na figura 1.7 a seguir:

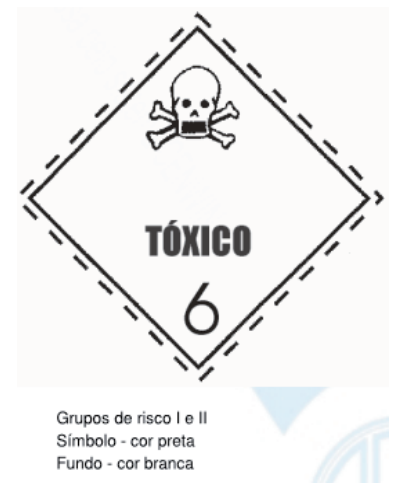

Figura 1.7. Rótulo de risco Classe 6

- Substâncias tóxicas. Fonte: Anexo A da NBR 7500/2000.
Além do rótulo de risco, a NBR 7500 trata do painel de segurança, sobre as cores empregadas no painel de segurança (Anexo F), dimensões do painel (Anexo $\mathrm{G}$ ), exemplos de painéis (Anexo $\mathrm{H}$ ) e tipos de algarismos a empregar (Anexo I).

AABNT NBR 8286:2000 especifica as condições necessárias para o emprego da sinalização nas unidades de transporte e de rótulos nas embalagens de produtos perigosos. Esta NBR orienta onde devem ficar nos veículos de transportes o painel de segurança, onde figuram, na parte superior, o número de identificação de risco do produto e, na parte inferior, o número de identificação do produto (número de risco e número ONU, conforme capítulo 4 da Portaria $n^{\circ} 204$ do Ministério dos Transportes).

O capitulo 4 da portaria $n^{\circ} 204$ do Ministério dos Transportes apresenta a relação de produtos perigosos. $\mathrm{O}$ número de risco, item 4.2 desta portaria, indica o número do grau de risco e seus respectivos significados. O número de risco para lâmpadas fluorescentes é o " 60 " e o significado "Produto nocivo ou tóxico".

Portanto, os materiais classificados como resíduos perigosos devem ser acondicionados em recipientes da cor laranja. As lâmpadas devem ser separadas por tipo e acondicionadas em sua embalagem original ou envoltas em papelão, preferencialmente em lotes de 20 a 30 . O armazenamento deve ser elaborado em conjunto com a área de segurança e havendo contaminação de EPI eles serão acondicionados em recipiente apropriado para posterior descarte.

Para iniciar o processo de armazenamento correto das lâmpadas foram estudados alguns materiais que poderiam servir de recipiente para acondicionamento das LFs, como: - container de lixo para armazenamento do resíduo urbano; - elaboração de projeto de conjunto de tubos de PVC com diâmetro grande; - reaproveitamento de conjunto de tubos de papelão com diâmetro grande que são descartados por gráficas como resíduos; - elaboração de projeto com pneus empilhados; - elaboração de projeto de caixa elaborada com garrafas PETs, sucata de freezer sem motor; e sucatas de armários metálicos de arquivos.

Após análise das possibilidades optou-se pela utilização de sucatas de armários metálicos de propriedade da empresa B. A caixa escolhida foi então recuperada, cortada, lixada, pintada e adaptada para que pudesse acondicionar as lâmpadas de forma prática e segura. Paralelamente a reforma da caixa metálica foi feita a elaboração das placas de sinalização e identificação do produto a ser colocado no recipiente, conforme orientações da ABNT NBR. A figura 1.8 a seguir ilustra o processo de elaboração a caixa metálica para armazenamento de lâmpadas. 


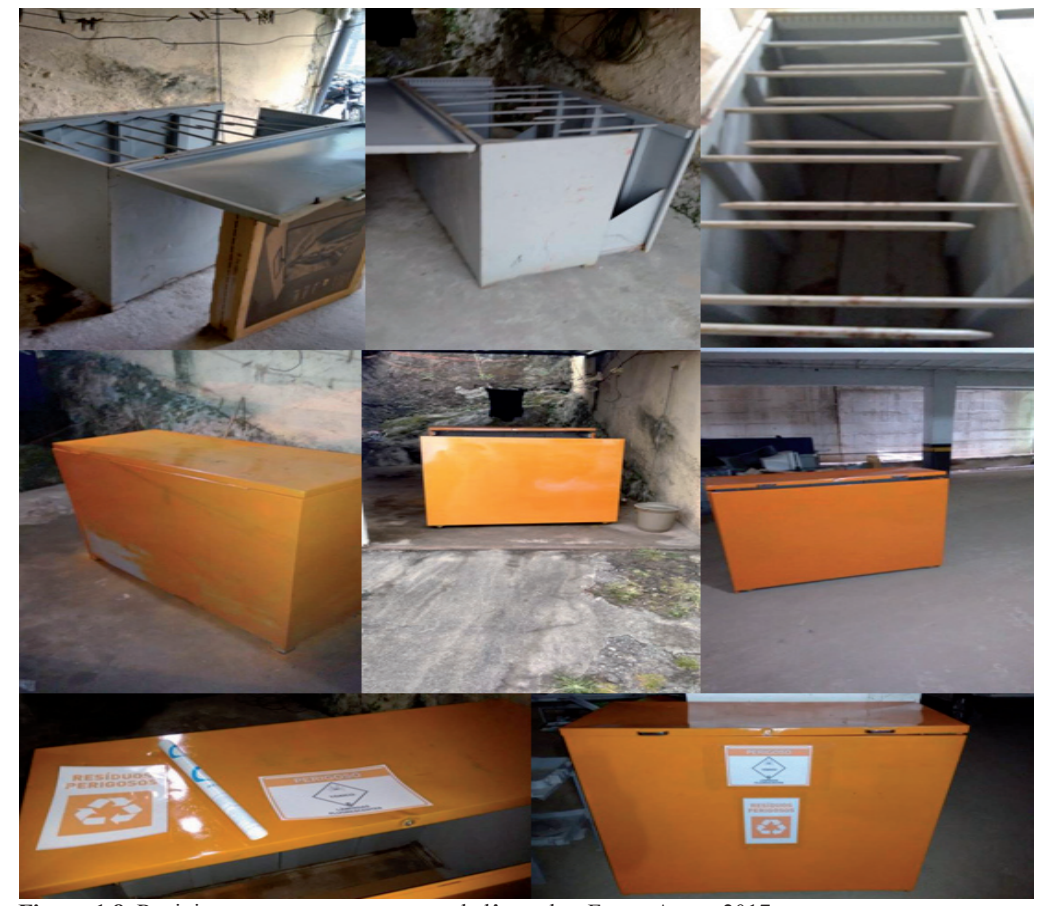

Figura 1.8. Recipiente para armazenamento de lâmpadas. Fonte: Autor, 2017.

Após o término da elaboração do recipiente e posicionamento do mesmo no local escolhido, foi iniciado o trabalho de manuseio das LFs. As lâmpadas foram embaladas em suas embalagens originais de papelão, em conjuntos de 20 a 30 lâmpadas e amarradas com fita plástica para facilitar o manuseio das mesmas até serem colocadas no recipiente próprio. O manuseio foi feito com uso dos EPIs necessários para execução do trabalho com segurança, são eles: óculos, luva, máscara, vestimenta e calçado de proteção. Posteriormente, os conjuntos de lâmpadas foram devidamente inseridos na caixa metálica, visando sempre a proteção do meio ambiente e a saúde humana, e fechada. A figura 1.9 a seguir apresenta os conjuntos de lâmpadas envolvidas em papelão preparadas para serem armazenadas.

Por fim, a caixa foi fechada e o trabalho de

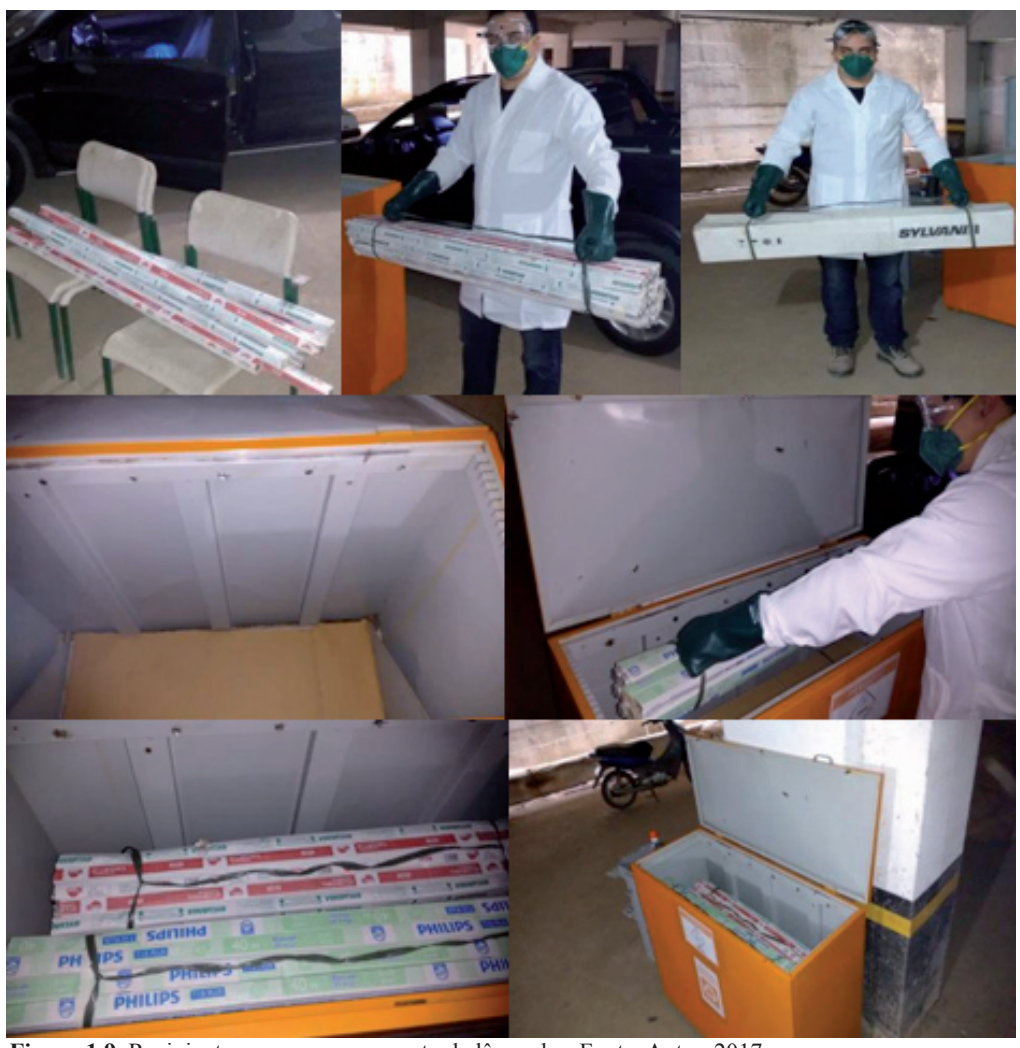

Figura 1.9. Recipiente para armazenamento de lâmpadas. Fonte: Autor, 2017. 


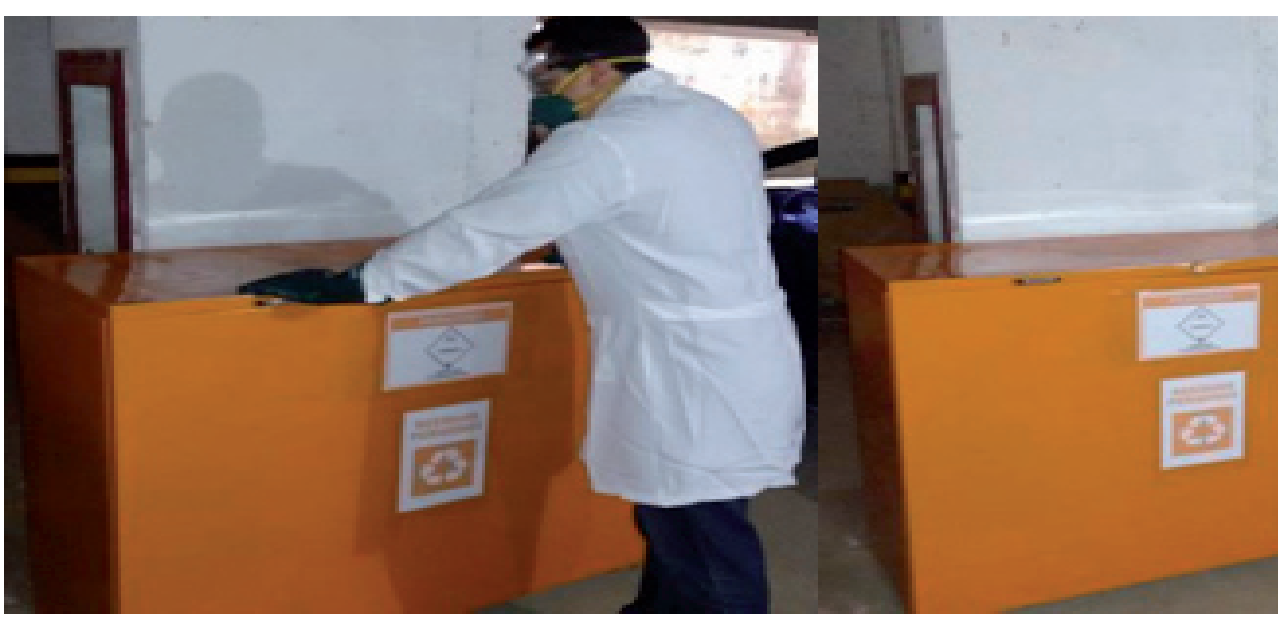

Figuras 1.10. Término das atividades de armazenamento das LFs. Fonte: Autor, 2017.

armazenamento encerrado, conforme ilustrado na figura 1.10 a seguir.

\section{Considerações finais e conclusão}

Através deste estudo foi possível verificar que, com o aumento do número de lâmpadas no mercado, torna-se necessário a estruturação de medidas de segurança para reverter o cenário atual de manuseio indevido de lâmpadas de vapor e descarte inconsciente da sociedade no lixo comum que tem como destino final os aterros sanitários, e consequentemente a poluição do meio ambiente, ar, água e solo.

Torna-se então necessária a criação de um sistema estruturado de informações sobre os risco destas lâmpadas, para prevenção contra acidentes e o controle da geração de resíduos, que atualmente estima-se ser mais de 200 milhões de unidades.

É comprovada a necessidade da conscientização da sociedade visto que alguns componentes de lâmpadas são nocivos e quase todos os componentes das lâmpadas são recicláveis e que de acordo com a Política Nacional de Resíduos Sólidos de 2010.

Verifica-se com este trabalho a necessidade da padronização dos procedimentos de segurança para trabalhadores envolvidos em todo processo das lâmpadas, desde sua fabricação até seu descarte final.

As políticas públicas voltadas à informação da sociedade sobre os efeitos tóxicos do mercúrio e a forma correta de manuseio e descarte ainda não são suficientes. Desta forma, estudos e esforços adicionais devem existir no sentido de melhor equacionar a questão da segurança com lâmpadas. É fundamental a inserção da educação ambiental na problemática de descarte de LF, com esclarecimentos para a sociedade sobre os efeitos do mercúrio, medidas de segurança e de pós-consumo, como a destinação final adequada.

Acredita-se que este artigo possa contribuir para a conscientização dos membros participantes da Universidade Severino Sombra e dos moradores do município de Vassouras, para que seja evitado acidentes com trabalhadores de empresas, acidentes em residências, perigos com coletores de lixo devido ao risco de cortes, perigos com crianças que manuseiam indevidamente lâmpadas para fazer cerol, podendo se machucar e causar mortes com linhas de pipas com cerol em motociclistas e pedestres e o envio deste resíduo perigoso e tóxico ao aterro deste município. Espera-se também que este trabalho seja publicado em revistas, feiras, simpósios e jornadas para disseminar todas as informações e aumentar o público abrangido em busca da educação e conscientização da problemática.

Considera-se que a visão geral proporcionada por este trabalho permitirá razoável posicionamento do leitor quanto às ações de operacionalização na gestão de resíduos de lâmpadas fluorescentes pós consumo para melhoria das atuais formas de descarte para um meio ambiente seguro e sustentável.

\section{Referência bibliográficas}

ABNT NBR 7500:2000 - Símbolos de risco e manuseio para o transporte e armazenamento de materiais. Disponível em $<\mathrm{http}$ ://www2.fct.unesp. $\mathrm{br} /$ docentes/plan/crisrizk/Gerenciamento $\% 20 \mathrm{de} \% 20$ Residuos $\% 20$ Solidos/ NBR_7500\%20-\%20simbolo\%20de\%20risco.PDF> Acesso em 14.05.2016

ABNT NBR 8286:2000 - Emprego da sinalização nas unidades de transporte e de rótulos nas embalagens de produtos perigosos. Disponível em <http://www2.fct.unesp.br/docentes/plan/crisrizk/Gerenciamento $\% 20$ de $\% 20$ Residuos $\% 20$ Solidos/NBR 8286\%20-\%20sinalizacao $\% 20 \mathrm{de} \% 20$ perigo $\% 20 \mathrm{de} \% 20$ residuos.PDF $>$ Acesso em 14.05.2016

ABNT NBR 10.004:2004 - Resíduos sólidos - Classificação. Disponível em <http://www.videverde.com.br/docs/NBR-n-10004-2004.pdf> Acesso em 14.05.2016 
BASTOS, F. C. (2011). Análise da política de banimento de lâmpadas incandescentes do mercado brasileiro. (Dissertação de Mestrado em Ciências em Planejamento Energético), Universidade Federal do Rio de Janeiro/ COPPE/ Programa de Planejamento Energético, Rio de Janeiro, RJ.

CARNEIRO, D. M. R. (2010). Da loucura dos gatos dançantes ao curtocircuito do século XXI: o mercúrio contido nas lâmpadas e a importância da educação no processo de gestão ambiental. (Dissertação de Mestrado em Desenvolvimento Sustentável - Área de concentração em educação e gestão ambiental). Universidade de Brasília - Centro de Desenvolvimento Sustentável. Unb Brasília/DF.

FERREIRA, R. A. F. (2010). Manual de Luminotécnica. Apostila auxiliar da disciplina ENE-065 para o curso de engenharia elétrica da UFJF. Universidade Federal de Juiz de Fora, Juiz de Fora, MG.

JÚNIOR, W. A. D., \& WINDMOLLER, C. C. (2008). A questão do mercúrio em lâmpadas fluorescentes. In: Química Nova na Escola. Disponível em $<$ http://qnesc.sbq.org.br/online/qnesc28/04-QS-4006.pdf $>$. Acesso em: 22.fev.2016

LEI 12.305/2010 (LEI ORDINÁRIA) 02/08/2010 - Política Nacional de Resíduos Sólidos. Disponível em <http://www.mma.gov.br/port/conama/ legiabre.cfm?codlegi $=636>$ Acesso em 14.05.2016

LIMA, E. R. Z., COLON, J. C., \& SOUZA, M. T. (2009). Alterações auditivas em trabalhadores expostos a mercúrio. In: Revista CEFAC, São Paulo, v.11, Supl1, 62-67. Disponível em <http://www.scielo.br/scielo.php?script=sci arttext\&pid=S1516-18462009000500010\&lng=en\&nrm=iso $>$. Acesso em: 22.fev. 2016

SILVA, F. R. (2013). Impactos Ambientais Associados à Logística Reversa de Lâmpadas Fluorescentes. In: InterfacEHS - Revista de Saúde, Meio Ambiente e Sustentabilidade. 8(1): 42-69. Disponível em <http://www. revistas.sp.senac.br/index.php/ITF/article/viewFile/320/302>. Acesso em: 22.fev. 2016 